\title{
Echinococcus granulosus (sensu stricto) (G1, G3) and E. ortleppi (G5) in Pakistan: phylogeny, genetic diversity and population structural analysis based on mitochondrial DNA
}

Mughees Aizaz Alvi ${ }^{1}$, John Asekhaen Ohiolei ${ }^{1}$, Muhammad Saqib², Li Li ${ }^{1}$, Muhammad Haleem Tayyab², Anum Aizaz Alvi ${ }^{3}$, Yan-Tao Wu' ${ }^{1}$ Bao-Quan Fu' ${ }^{1}$, Hong-Bin Yan ${ }^{1 *}$ and Wan-Zhong Jia ${ }^{1 *}$

\begin{abstract}
Background: Cystic echinococcosis (CE) is a serious tapeworm infection caused by Echinococcus granulosus (sensu lato) which infects a wide range of animals and humans worldwide. Despite the millions of livestock heads reared in Pakistan, only a few reports on CE prevalence and even fewer on the genetic diversity are available for the country. Meanwhile, the available reports on the genetic diversity are predominantly based on short sequences of the cox 1 gene.

Methods: To close this knowledge gap, this study was designed to investigate the genetic diversity and population structure of Echinococcus spp. in Pakistan using the complete mitochondrial cytochrome c oxidase subunit 1 (cox1) and NADH dehydrogenase subunit 1 (nad1) genes.

Results: Based on BLAST searches of the generated cox 1 and nad 1 gene sequences from a total of 60 hydatid cysts collected from cattle $(n=40)$ and buffalo $(n=20), 52$ isolates were identified as E. granulosus (s.s.) $(\mathrm{G} 1, \mathrm{G} 3)$ and 8 as $E$. ortleppi (G5). The detection of the G5 genotype represents the first in Pakistan. The phylogeny inferred by the Bayesian method using nucleotide sequences of cox1-nad1 further confirmed their identity. The diversity indices indicated a high haplotype diversity and a low nucleotide diversity. The negative values of Tajima's $D$ and Fu's Fs test demonstrated deviation from neutrality suggesting a recent population expansion.

Conclusions: To the best of our knowledge, this report described the genetic variation of E. granulosus population for the first time in Pakistan using the complete cox 1 and nad 1 mitochondrial genes and confirms E. ortleppi as one of the causative agents of CE among livestock in Pakistan. While this report will contribute to baseline information for CE control, more studies considering species diversity and distribution in different hosts across unstudied regions of Pakistan are highly needed.
\end{abstract}

Keywords: Echinococcus granulosus, Echinococcus ortleppi, Pakistan, Genetic variation, Haplotype diversity, Phylogeny

\footnotetext{
*Correspondence: yanhongbin@caas.cn; jiawanzhong@caas.cn

1 State Key Laboratory of Veterinary Etiological Biology, National

Professional Laboratory of Animal Hydatidosis, Key Laboratory

of Veterinary Parasitology of Gansu Province, Lanzhou Veterinary Research

Institute, Chinese Academy of Agricultural Sciences, Lanzhou 730046,

Gansu, People's Republic of China

Full list of author information is available at the end of the article
}

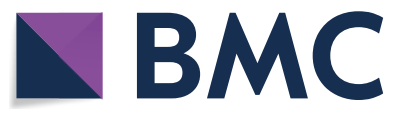

(c) The Author(s) 2020. This article is licensed under a Creative Commons Attribution 4.0 International License, which permits use, sharing, adaptation, distribution and reproduction in any medium or format, as long as you give appropriate credit to the original author(s) and the source, provide a link to the Creative Commons licence, and indicate if changes were made. The images or other third party material in this article are included in the article's Creative Commons licence, unless indicated otherwise in a credit line to the material. If material is not included in the article's Creative Commons licence and your intended use is not permitted by statutory regulation or exceeds the permitted use, you will need to obtain permission directly from the copyright holder. To view a copy of this licence, visit http://creativeco mmons.org/licenses/by/4.0/. The Creative Commons Public Domain Dedication waiver (http://creativecommons.org/publicdomain/ zero/1.0/) applies to the data made available in this article, unless otherwise stated in a credit line to the data. 


\section{Background}

Cystic echinococcosis (CE) is listed by the World Health Organization (WHO) as a neglected tropical disease having zoonotic connotations [1]. Echinococcus granulosus (sensu lato) is the etiological agent with a cosmopolitan distribution leading to heavy economic losses amounting for up to 3 billion USD per year [2] and human suffering [3]. Based on nucleotide sequence variation of the mitochondrial DNA, eight different genotypes and E. felidis within the E. granulosus complex have been recognized to infect different hosts [4]. Echinococcus granulosus (sensu stricto) (G1/G3), E. ortleppi (G5) and E. canadensis complex have the highest significance concerning Echinococcus infection in livestock population across the globe $[1,5]$. These species require two mammalian hosts to complete their life-cycle via a definitive canine host and an intermediate host (domestic or wild ungulate), while humans are considered to be accidental or dead-end hosts [6].

$\mathrm{CE}$ is endemic throughout the world including countries in Africa, Europe, South America, the Middle East and Central Asia [7, 8]. Pakistan is an agriculturedependent country and the livestock sector is an important pillar of the national economy contributing 11.2\% to the national GDP [9]. According to the latest livestock census, there are 47.8 million heads of cattle and 40 million heads of buffalo in the country. In the last four decades, there has been no comprehensive data on genetic characterization and molecular diversity of CE in Pakistan. From 1980 to 2015, only three molecular investigations on Echinococcus spp. have been reported in animals and were based on partial cox 1 gene sequences in addition to their limited geographical areas [10].

Given the high population of livestock, scarcity of genetic data and endemic status of $\mathrm{CE}$ in the adjoining countries, this study was designed to provide a better insight into the circulating genotypes and to describe the genetic population structure and diversity of Echinococcus spp. in animals in Punjab and Khyber Pakhtunkhwa provinces of Pakistan using the full-length $n a d 1$ and $\operatorname{cox} 1$ genes.

\section{Methods}

\section{Study areas}

Pakistan is located in South Asia bordered by Afghanistan, China, India, and Iran to the west, northeast, east, and southwest, respectively. Hydatid cyst sampling was conducted in Lahore, Faisalabad, and Peshawar (Fig. 1). Lahore is the provincial capital of Punjab and one of the most populous cities in Pakistan. Faisalabad is the third-most-populous city in Pakistan and the secondlargest in the eastern province of Punjab. Historically, it is one of the first planned cities within British India and often regarded as the Manchester of Pakistan because of massive industrialization. Peshawar is the capital and largest city of the Khyber Pakhtunkhwa Province.

\section{Parasite material}

Hydatid cysts were collected during September 2019 from abattoirs under the jurisdiction of municipal corporations of Lahore, Faisalabad and Peshawar districts. Before sampling, the stationed veterinary officers were informed about the nature of the study. Inspection of the carcasses was performed, and a total of 60 hydatid cysts were collected. All cysts were of cattle $(n=40)$ and buffalo $(n=20)$ origin. Unfortunately, no cysts were found in sheep and goats slaughtered during this period. The cysts were transported to the Department of Clinical Medicine and Surgery, University of Agriculture, Faisalabad, Pakistan, under refrigerated conditions for further processing.

\section{DNA extraction, amplification and sequencing of isolates}

Hydatid cysts were thoroughly cleaned with $75 \%$ ethanol. Germinal layers were washed with phosphate-buffered saline (PBS). Moreover, protoscoleces were repeatedly washed in PBS as described previously [11] and stored until use. DNA extraction was carried out on cut pieces of germinal layers and protoscoleces using the Qiagen Blood and Tissue Kit (Qiagen, Hilden, Germany) according to the manufacturer's instructions. Amplification of the complete mitochondrial complete cox 1 gene (1608 bp) using forward primer (5'-ATT ATA GAA AAT TTT CGT TTT ACA CGC-3') and reverse primer (5'-AAG CAT GAT GCA AAA GGC AAA TAA ACC-3') and complete nad 1 gene (894 bp) using forward primer (5'-ATT ATA GAA AAT TTT CGT TTT ACA CGC-3') and reverse primer (5'-ATT CAC AAT TTA CTA TAT CAA AGT AAC C-3') [12] was carried out for all isolates. Positive and negative controls were also used. The PCR conditions were carried out as previously described [13] in a final volume of $25 \mu \mathrm{l}$ consisting of $5 \mu \mathrm{l}$ of $5 \times \mathrm{Taq}$ buffer, 10 pmol of each primer, $0.2 \mathrm{mM}$ dNTPs, $0.5 \mu \mathrm{l}$ of Ex Taq DNA polymerase ( $5 \mathrm{U} / \mu \mathrm{l}$; TaKaRa, Kusatsu, Japan), $2 \mathrm{mM} \mathrm{MgCl}$, $0.5 \mu \mathrm{l}$ of genomic DNA extract ( $\geq 20 \mathrm{ng}$ ) and RNAse free water to make up the final volume. Amplicons were visualized in a $1.5 \%(\mathrm{w} / \mathrm{v})$ agarose gel stained with GelRed ${ }^{\mathrm{TM}}$ (Biotium, Fremont, USA). Five microliters of the amplicon were used for this purpose while the rest was used for sequencing in an ABI3730XI DNA Analyser (Beijing Tsingke Biotechnology Co., Ltd., Beijing, China).

\section{Molecular analysis}

DNA sequence alignment and manual examination for misread nucleotide bases were conducted in Unipro UGENE v1.32.0 software [14] while the identity of each isolate was confirmed with their nucleotide sequences 


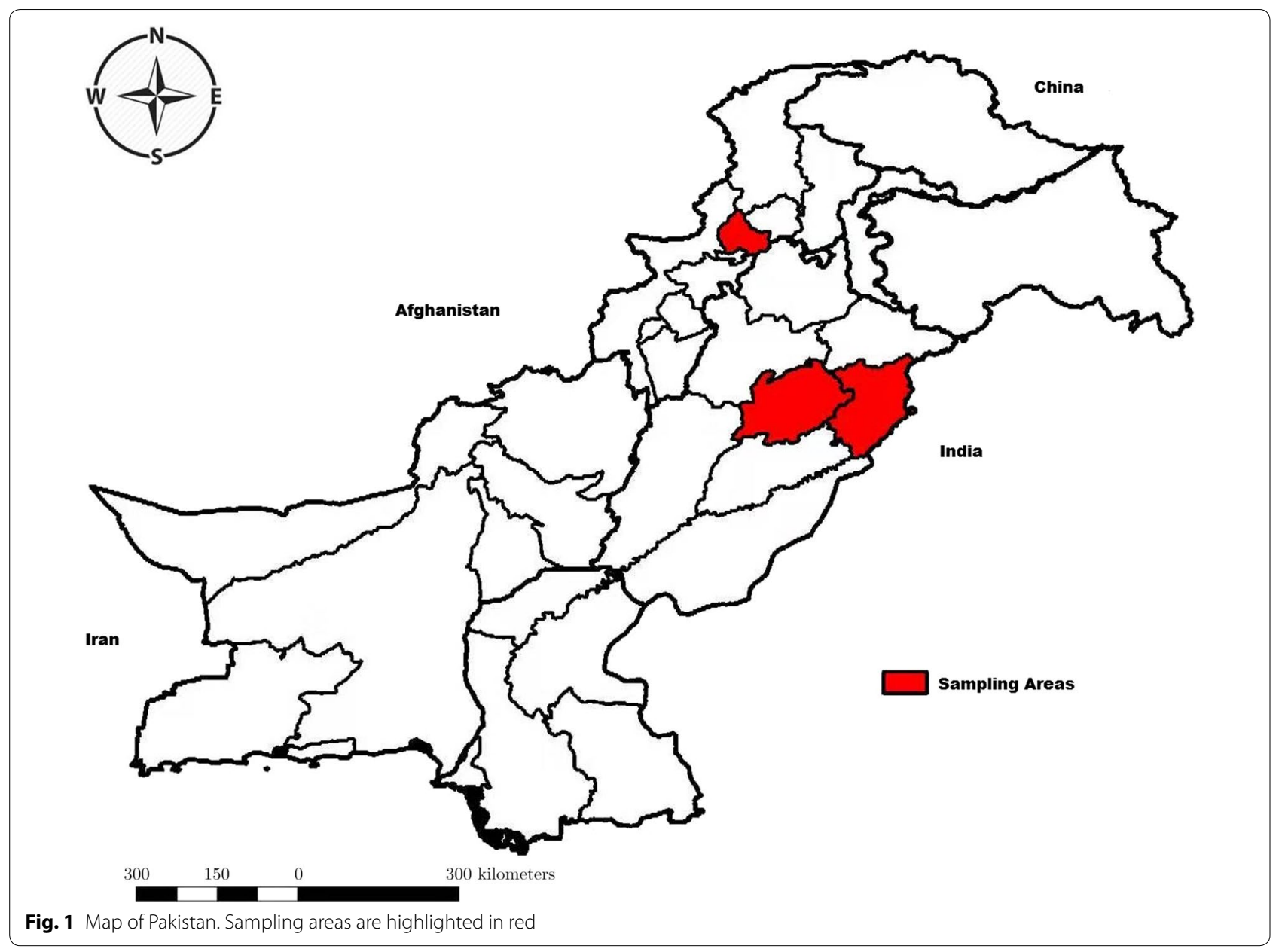

using the NCBI BLAST program (https://blast.ncbi.nlm. nih.gov/Blast.cgi).

\section{Population genetic analysis}

Diversity indices such as number of haplotypes (h), haplotype diversity $(\mathrm{Hd})$ and nucleotide diversity $(\pi)$ were estimated using DnaSP v.6. The neutrality indices (Tajima's $D$ and Fu's Fs) $[15,16]$ were estimated in DnaSP v.6 [17]. Median-joining network [18] was inferred based on mitochondrial nad $1, \operatorname{cox} 1$ and $n a d 1-\operatorname{cox} 1$ gene sequences using PopART (http://popart.otago.ac.nz) for intraspecific data analysis revealing several connections between haplotypes representing possible missing mutational links.

\section{Phylogenetic analyses}

The phylogenetic relationships between haplotypes were inferred by Bayesian method based on the nad1cox1 dataset using MrBayes v.3.1.1 [19]. Markov Chain
Monte Carlo (MCMC) sampling was used to assess the posterior distribution of parameters with a chain length of 5,000,000 states with parameters logged at every 1000 states and 25\% discarded as 'burn-in'. TreeView v.1.6.6 (http://taxonomy.zoology.gla.ac.uk/rod/treeview.html) was used to display the tree.

\section{Results}

Amplification of the $n a d 1$ and $\operatorname{cox} 1$ gene yielded PCR products of approximately $1400 \mathrm{bp}$ and $2000 \mathrm{bp}$, respectively. Nucleotide sequences of all 60 isolates analyzed in this study were aligned with reference sequences of each genotype within E. granulosus (s.l.) retrieved from GenBank. A total of 3 genotypes of Echinococcus were found: G1 $(n=14) ; \mathrm{G} 3(n=38)$; and G5 $(n=8)$. Comparative data on organ location, cysts fertility and genotypes of $E$. granulosus and E. ortleppi isolates are shown in Table 1. 
Table 1 Comparative data on organ location, cysts fertility and genotypes of Echinococcus granulosus and E. ortleppi isolates

\begin{tabular}{|c|c|c|}
\hline $\begin{array}{l}\text { Organ of cyst } \\
\text { isolation and fertility }\end{array}$ & $\begin{array}{l}\text { Cattle } \\
\text { No. of cysts (genotype count) }\end{array}$ & $\begin{array}{l}\text { Buffalo } \\
\text { No. of cysts } \\
\text { (genotype } \\
\text { count) }\end{array}$ \\
\hline Lungs fertile & $3(2 \mathrm{G} 1,1 \mathrm{G} 5)$ & $1 \mathrm{G} 3$ \\
\hline Lungs infertile & $32(5 \mathrm{G} 1,23 \mathrm{G} 3,4 \mathrm{G} 5)$ & $15(4 \mathrm{G} 1,11 \mathrm{G} 3)$ \\
\hline Liver fertile & $1 \mathrm{G} 5$ & $2 \mathrm{G} 3$ \\
\hline Liver infertile & 4 (2 G1, 2 G5) & $2(1 \mathrm{G} 1,1 \mathrm{G} 3)$ \\
\hline Total & 40 (9 G1, 23 G3, 8 G5) & $20(5 \mathrm{G} 1,15 \mathrm{G} 3)$ \\
\hline
\end{tabular}

\section{Nucleotide polymorphism}

The newly generated sequences of $E$. granulosus (s.s.) showed a total of 42 mutation sites $($ nad $1=13$ and $\operatorname{cox} 1=29$ ) with 23 parsimony informative sites (nad $1=8$ and $\operatorname{cox} 1=15$ ). Among the 52 E. granulosus (s.s.) isolates, 12 and 23 haplotypes were found for nad 1 and cox 1 genes, respectively while on concatenation of both gene sequences (nad1-cox 1,2502 bp) 34 distinct haplotypes were identified.

In the median-joining network for nad 1 gene sequences, haplotype PAK-H4 had a central position and comprised $32.69 \%(17 / 52)$ of the total population with not more than 4 mutational differences from the other haplotypes (Fig. 2). For the cox 1 gene, the haplotype PAK-H3 was at the centre of the network, constituting $21.15 \%(11 / 52)$ of the total population with up to 14 mutational differences from the other haplotypes (Fig. 3). Of the 34 haplotypes based on the concatenated sequences of both genes, PAK-H18 was at the

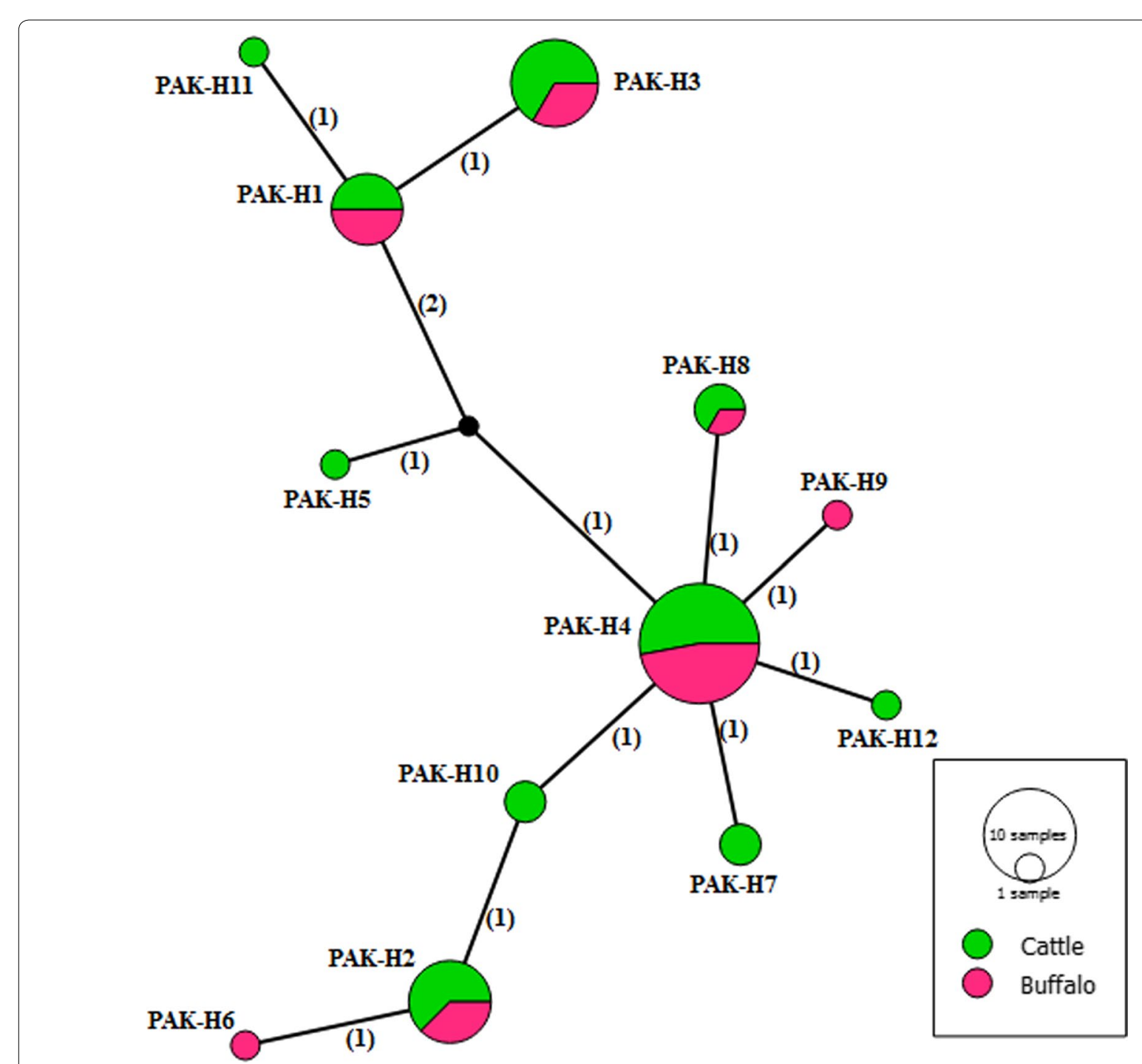

Fig. 2 Median-joining network of Echinococcus granulosus (s.s.) isolates from Pakistan based on complete nad1 gene sequences. Circle sizes are proportional to the haplotype frequencies. Numbers in parentheses represent the number of mutations. Small black circles are median vectors 


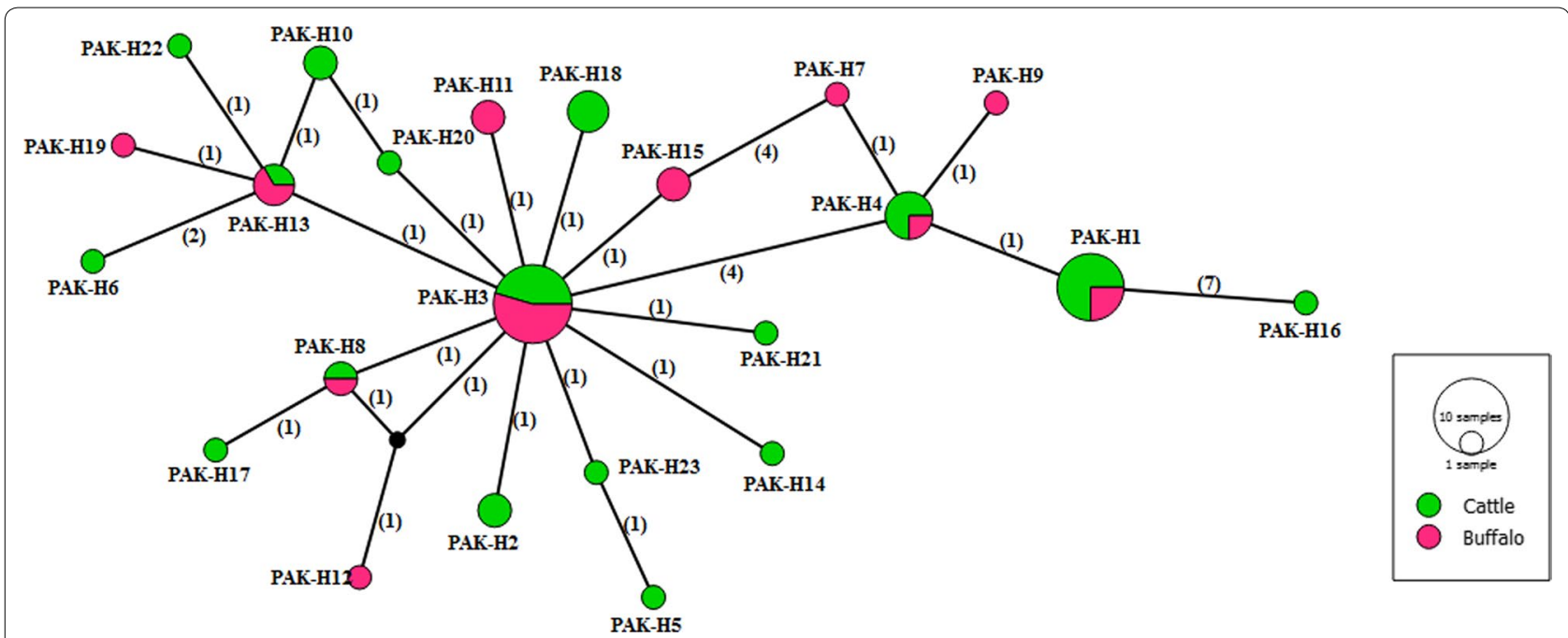

Fig. 3 Median-joining network of Echinococcus granulosus (s.s.) isolates from Pakistan based on complete cox1 gene sequences. Circle sizes are proportional to the haplotype frequencies. Numbers in parentheses represent the number of mutations. Small black circles are median vectors

centre of the network and constituted $9.61 \%(5 / 52)$ of the total population with a maximum mutational difference of 16 from other haplotypes (Fig. 4). The central haplotype from all three networks comprised isolates from both hosts but did not constitute the majority of the population. The observed nucleotide polymorphism between haplotypes resulted in an amino acid change (see Additional file 1: Tables S1, S2).

Concerning E. ortleppi, sequence analysis revealed a total of 17 mutation sites (nad $1=5$ and $\operatorname{cox} 1=12$ ) with 11 parsimony informative sites. Out of the 8 samples, 2 and 5 haplotypes were found for $n a d 1$ and $\operatorname{cox} 1$ genes, respectively, while 6 distinct haplotypes were observed for the nad1-cox1 (2502 bp) concatenated sequences dataset.

Representative nad 1 and $\operatorname{cox} 1$ haplotype sequences from this study were deposited in the GenBank database under the accession numbers MN886252-MN886293.

\section{Population indices}

The nucleotide diversity and neutrality indices for the entire E. granulosus (s.s.) and E. ortleppi populations were calculated based on the sequences of nad1, cox 1 , and nad1-cox 1 genes. For E. granulosus (s.s.), a low nucleotide $(\pi)$ and high haplotype diversity $(\mathrm{Hd})$ was observed for nad1 and cox 1 genes in both cattle and buffalo. Overall, $\mathrm{Hd}$ and $\pi$ were as follows: nad $1(\mathrm{Hd}=0.834, \pi=0.00293)$ and $\operatorname{cox} 1(\mathrm{Hd}=0.925$, $\pi=0.00223$ ) while $n a d 1-\operatorname{cox} 1 \pi$ and Hd were 0.00248 and 0.972 , respectively. Fu's Fs was negative and insignificant $(P>0.05)$ for the $n a d 1$ gene. In contrast, it was significant $(P<0.05)$ for $\operatorname{cox} 1$ and the concatenated nad $1-\operatorname{cox} 1$ sequences. Tajima's $D$ were negative and insignificant for the entire population (Table 2).

For E. ortleppi, overall nad1-cox $1 \pi$ and Hd were 0.00257 and 0.893 , respectively with insignificant Fu's Fs $(0.032)$ and Tajima's $D(-0.10063)$ for the entire population (Table 3).

\section{Phylogenetic analysis}

The resulting sequences of the different genotypes/ species with those retrieved from GenBank were used to construct a phylogenic tree. The Bayesian phylogeny based on a dataset of the concatenated nad $1-\operatorname{cox} 1$ sequences placed all the Pakistani E. granulosus (s.s.) and E. ortleppi (G5) isolates in the same clusters with the respective reference genotype sequences from GenBank (Fig. 5). The Bayesian phylogenetic inference confirmed their genotype/species status as distant from other Echinococcus species.

\section{Discussion}

Mitochondrial DNA has played an extensive role in investigating intraspecific variations and other population genetic studies because of its conserved structure, maternal inheritance, high mutation rate, absence of recombination, and high evolutionary rate [20-22]. In this study, we report the genetic diversity of $E$. granulosus (G1/G3) and E. ortleppi (G5) isolates from buffalo and cattle collected from different slaughterhouses in two provinces of Pakistan based on the complete sequences of two mitochondrial genes, cox 1 and nad 1 . Previously, in Pakistan, the genetic variation and diversity of Echinococcus spp. have mostly been assessed based on partial gene sequences [10, 23-25]. 


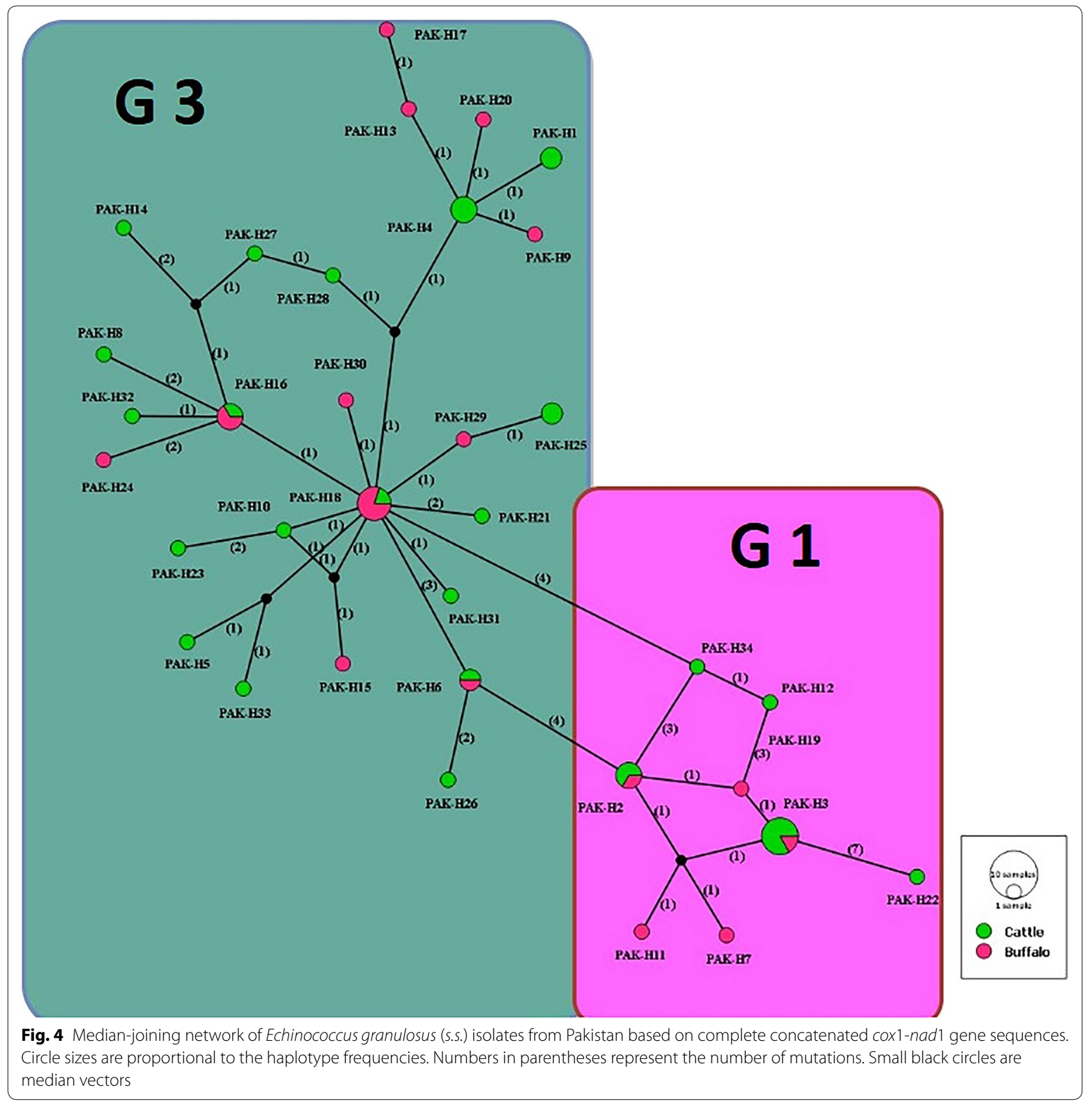

Based on the complete gene sequences, we found the G3 genotype as the most prevalent genotype (38/60) infecting the Pakistani bovine population followed by G1 $(14 / 60)$ and G5 (8/60). The results are concordant with a previous study conducted in a neighboring country (India) where the G3 (71.8\%) was also found to be the most common genotype [26]. Conversely, in China [27], Iran [28], Turkey [29] and Brazil [30] the G1 genotype is reportedly the predominant genotype with $95.74 \%$, $87.5 \%, 66 \%$ and $77.4 \%$ prevalence, respectively.
As far as we know, available data on the genetic diversity of Echinococcus in Pakistan has been predominantly based on partial sequences of the cox 1 gene which limits a thorough comparison of the genotypic diversity scenario in Pakistan with its adjoining countries. The length of the gene under study has been reported to potentially affect the outcomes of genetic diversity investigations $[31,32]$. For example, using a fragment of the $\operatorname{cox} 1$ gene in a study conducted on 223 East European and 89 Italian isolates, 24 and 7 haplotypes, respectively were observed [33], while in another study on 69 Argentine isolates 7 
Table 2 Diversity and neutrality indices for Echinococcus granulosus (s.s.) populations from Pakistan

\begin{tabular}{|c|c|c|c|c|c|c|c|c|c|}
\hline \multirow[t]{2}{*}{ Index } & \multicolumn{3}{|c|}{ nad1 (894 bp) } & \multicolumn{3}{|c|}{ cox1 (1608 bp) } & \multicolumn{3}{|c|}{ nad1-cox1 (2502 bp) } \\
\hline & Cattle & Buffalo & Overall & Cattle & Buffalo & Overall & Cattle & Buffalo & Overall \\
\hline No. of isolates & 32 & 20 & 52 & 32 & 20 & 52 & 32 & 20 & 52 \\
\hline No. of mutations & 11 & 9 & 13 & 24 & 12 & 29 & 35 & 21 & 42 \\
\hline Parsimony informative sites & 8 & 6 & 8 & 12 & 9 & 15 & 20 & 15 & 23 \\
\hline No. of haplotypes & 10 & 7 & 12 & 17 & 11 & 23 & 23 & 16 & 34 \\
\hline Haplotype diversity (Hd) & 0.865 & 0.805 & 0.834 & 0.933 & 0.900 & 0.925 & 0.968 & 0.963 & 0.972 \\
\hline Nucleotide diversity ( $\pi$ ) & 0.00304 & 0.00287 & 0.00293 & 0.00247 & 0.00185 & 0.00223 & 0.00267 & 0.00222 & 0.00248 \\
\hline Tajima's D & -0.01118 & 0.04283 & -0.26602 & -1.17027 & -0.42821 & -1.45764 & -0.83097 & -0.23976 & -1.13030 \\
\hline Fu's Fs & -1.672 & -0.453 & -2.207 & $-6.720^{*}$ & $-3.927^{*}$ & $-11.823^{*}$ & $-10.559^{*}$ & $-7.575^{*}$ & $-21.380^{*}$ \\
\hline
\end{tabular}

* Significant $(P<0.05)$

Table 3 Diversity and neutrality indices for Echinococcus ortleppi population of cattle origin from Pakistan

\begin{tabular}{llll}
\hline Index & nad1 (894 bp) & cox1 (1608 bp) & nad1-cox1 (2502 bp) \\
\hline No. of isolates & 8 & 8 & 8 \\
No. of mutations & 5 & 12 & 17 \\
Parsimony informative sites & 5 & 11 & 11 \\
No. of haplotypes & 2 & 5 & 6 \\
Haplotype diversity $(\mathrm{Hd})$ & 0.25 & 0.857 & 0.893 \\
Nucleotide diversity $(\pi)$ & 0.0014 & 0.00322 & 0.00257 \\
Tajima's D & -1.5952 & 0.59845 & -0.1006 \\
Fu's Fs & 2.407 & 0.867 & 0.032
\end{tabular}

haplotypes were observed [34]. Similarly, an investigation conducted on 112 isolates from the Sindh Province of Pakistan based on partial cox 1 gene sequence resulted in 5 haplotypes [24]. In the present study, we found 34 haplotypes among the investigated E. granulosus (s.s.) population, based on the concatenated genes. The analysis of both mitochondrial genes (nad 1 and cox 1 ) revealed a considerable high level of genetic variation. Higher haplotype diversity and nucleotide diversity were recorded for cox 1 and nad 1 gene, respectively of cattle isolates as compared to buffalo isolates. Overall, the diversity and neutrality indices based on the concatenation of both genes were higher in cattle. The radial population structure from the median-joining network observed in the present study differs from the star-like population structure reported in Argentina [34], China [35, 36] and Tunisia [37] where the G1 genotype was found to be preponderant, whereas it was similar to the population structure of E. granulosus (s.s.) recently reported in Pakistan where the G3 genotype was found to be preponderant [38].

The G5 genotype has been reported in humans in Argentina, Brazil, China, France, India, Mexico and the Netherlands [31, 39-41] indicating that this is an important genotype in terms of public health significance. In this study, to the best of our knowledge, we confirm for the first time, the presence of the 'cattle' strain (G5) of the E. granulosus (s.l.) complex in central Pakistan. This report is also in line with previous observations regarding the prevalence of E. ortleppi (G5) in a few Asian countries. For example, the G5 genotype has been reported in cattle from India, Iran, Bhutan, and Nepal $[26,42-44]$ and recently in a human from China [41]. Host distribution and prevalence of the G5 genotype are highly variable across the world. Echinococcus ortleppi (G5) infecting cattle has been reported from Brazil [45], Uruguay [46], France [39], Italy [5], Sudan [47], Ethiopia [48] and Kenya [49]. Out of eight isolates of G5 collected in this study, five were of lung origin which is in line with a molecular survey conducted in Brazil, which had a prevalence of $43.4 \%$ for the G5 genotype in cattle, with most of the isolates found in the lungs [45]. Overall, the genetic diversity and neutrality indices based on the mitochondrial genes ( $\operatorname{cox} 1$ and nad1) were relatively similar to the genetic diversity of E. ortleppi in eastern and southern Africa [50].

The neutrality test based on both genes showed negative insignificant values of Tajima's $D$, indicating an 


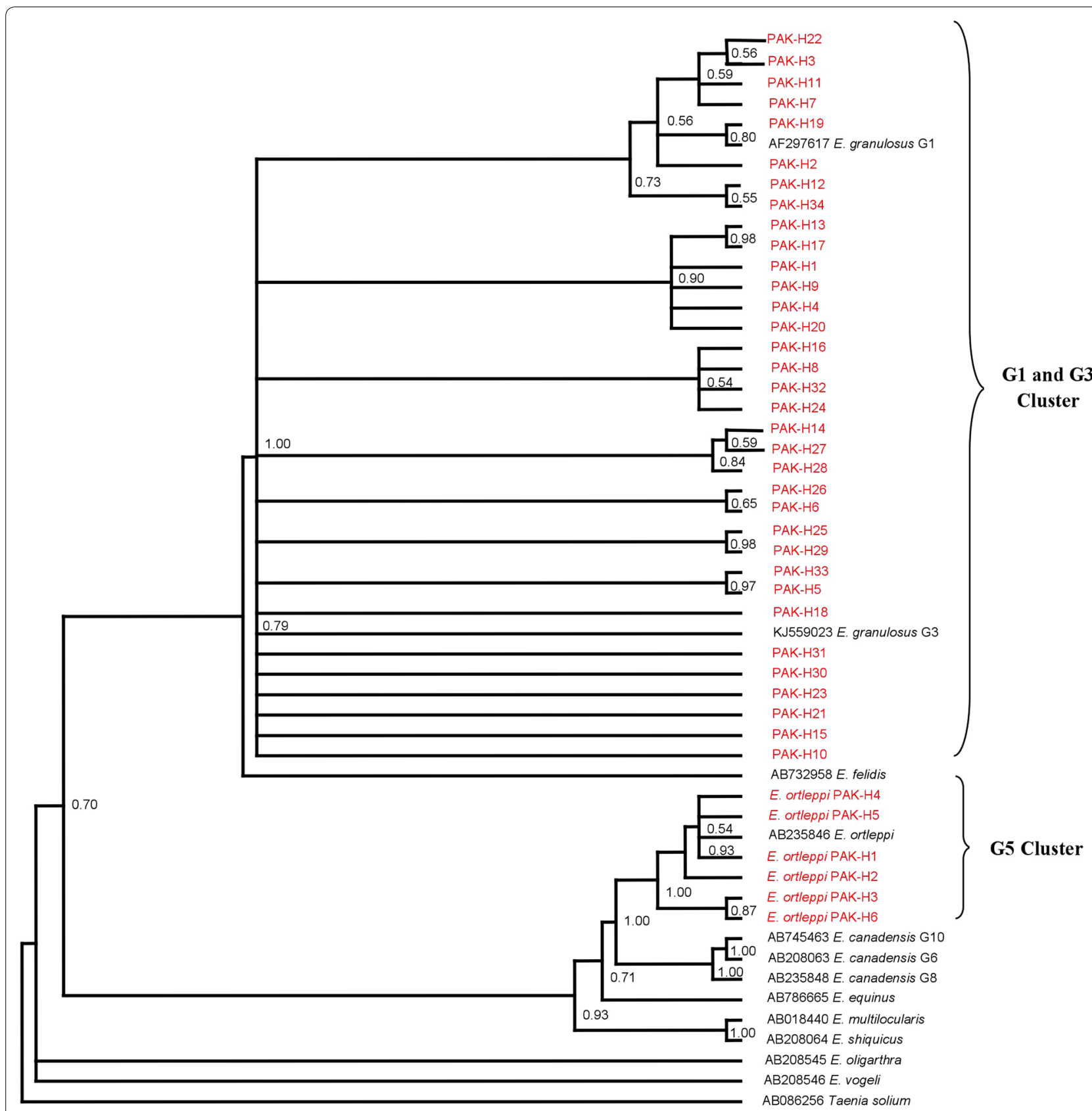

Fig. 5 Bayesian phylogeny of Pakistani Echinococcus granulosus (G1, G3 and G5) isolates inferred from the cox1-nad1 (2502 bp) concatenation. Taenia solium was used as the outgroup. Red color indicates E. granulosus haplotypes isolated in this study. Posterior probability values are depicted at the nodes

excess of low-frequency polymorphism which suggests a recent population expansion. The values of Fu's Fs test were negative and significant for $\operatorname{cox} 1$ and the concatenated nad1-cox 1 sequences, indicating an excess number of alleles, as would be expected during genetic hitchhiking or a recent population expansion. The overall negative values of both Tajima's $D$ and Fu's Fs tests also confirm an excess of rare mutations within E. granulosus (G1/G3) populations. In contrast, the E. ortleppi (G5) population showed an insignificant negative Tajima's $D$ and insignificantly positive Fu's Fs.

In the present study, high haplotype diversity suggests a considerable amount of genetic differentiation between the haplotypes as seen in the median-joining network. 
These results, i.e. the combination of the low nucleotide and high haplotype diversity, suggest a rapid population spread out from a small population size, as described in a previous study [40].

Phylogenetic analysis of the concatenated gene sequences also confirmed the identity of the isolates from buffalo and cattle as E. granulosus (G1/G3) and E. ortleppi (G5), respectively as they clustered closely with respective Echinococcus species (G1-G10) sequences retrieved from GenBank. The basal site of the tree was occupied by Neotropical species, E. vogeli and E. oligarthra. The tree also confirmed the sister relationships between $E$. canadensis and E. ortleppi, and between E. shiquicus and E. multilocularis as previously described [51].

\section{Conclusions}

The study demonstrates the preponderance of the G3 genotype among all encountered genotypes/species of E. granulosus (s.s.) (G1, G3) and E. ortleppi (G5) and emphasizes the important role of this genotype in the distribution of $\mathrm{CE}$ among livestock and possibly in human populations. The detection of the G5 genotype also raises some public health concerns due to the increasing reports of human infections with this genotype. Furthermore, analysis of the complete $n a d 1$ and cox 1 gene sequences of E. granulosus (s.s.) population in Pakistan demonstrated a higher genetic variation than what was previously reported based on partial gene sequences.

\section{Supplementary information}

Supplementary information accompanies this paper at https://doi. org/10.1186/s13071-020-04199-8.

Additional file 1: Table S1. Echinococcus granulosus (s.s.) mitochondrial cox1 gene nucleotide sequence polymorphism and corresponding amino acid changes among haplotypes from cattle and buffalo. Table S2. Echinococcus granulosus (s.s.) mitochondrial nad1 gene nucleotide sequence polymorphism and corresponding amino acid changes among haplotypes from cattle and buffalo. Table S3. Echinococcus ortleppi mitochondrial cox 1 gene nucleotide sequence polymorphism among haplotypes from cattle. Table S4. Echinococcus ortleppi mitochondrial nad1 gene nucleotide sequence polymorphism among haplotypes from cattle.

\section{Abbreviations}

PBS: phosphate-buffered solution; PCR: polymerase chain reaction; cox1: cytochrome coxidase subunit 1 gene; nad1: NADH dehydrogenase subunit 1 gene; CE: cystic echinococcosis; MCMC: Markov Chain Monte Carlo; Hd: haplotype diversity.

\section{Acknowledgments}

We are thankful to Dr. Khurram Ashfaq, Dr. Imaad Rasheed and other supporting staff of the Department of Clinical Medicine and Surgery, University of Agriculture, Faisalabad for logistic support.

\section{Authors' contributions}

MAA, HBY, MS and WZJ conceived and designed the experiments. MAA, MS, MHT and AAA collected the samples. MAA, JAO, LL, YTW and HBY performed the experiments and data analyses. MAA wrote the first draft of the manuscript, and JAO, HBY, BQF and WZJ provided comments and constructive suggestions for revisions. All authors read and approved the final manuscript.

\section{Funding}

This study was supported by the National Key Research and Development Program of China (2017YFD0501301; 2018YFC1602504), and the Central Public-interest Scientific Institution Basal Research Fund (1610312017001; 1610312016012) for funding this study. This study was part of a PhD research supported by Lanzhou Veterinary Research Institute, Chinese Academy of Agricultural Sciences, the People's Republic of China.

\section{Availability of data and materials}

All data supporting the conclusions of this article are included within the article and its additional files. Representative nucleotide sequences of nad 1 and cox 1 genes from the present study are available in the GenBank database under the accession numbers MN886252-MN886293.

\section{Ethics approval and consent to participate}

Not applicable.

\section{Consent for publication}

Not applicable.

\section{Competing interests}

The authors declare that they have no competing interests.

\section{Author details}

1 State Key Laboratory of Veterinary Etiological Biology, National Professional Laboratory of Animal Hydatidosis, Key Laboratory of Veterinary Parasitology of Gansu Province, Lanzhou Veterinary Research Institute, Chinese Academy of Agricultural Sciences, Lanzhou 730046, Gansu, People's Republic of China. ${ }^{2}$ Department of Clinical Medicine and Surgery, University of Agriculture, Faisalabad, Pakistan. ${ }^{3}$ Institute of Pharmacy, Physiology and Pharmacology, University of Agriculture, Faisalabad, Pakistan.

Received: 7 January 2020 Accepted: 20 June 2020

Published online: 13 July 2020

\section{References}

1. Thompson RC. The taxonomy, phylogeny and transmission of Echinococcus. Exp Parasitol. 2008;1 19:439-46.

2. WHO. Echinococcosis. Geneva: World Health Organization; 2019. https:// www.who.int/news-room/fact-sheets/detail/echinococcosis. Accessed 27 Dec 2019.

3. Hammad SJ, Cavallero S, Milardi GL, Gabrielli S, Al-Nasiri FS. Molecular genotyping of Echinococcus granulosus in the North of Iraq. Vet Parasitol. 2018;249:82-7

4. Ahmed ME, Salim B, Grobusch MP, Aradaib IE. First molecular characterization of Echinococcus granulosus (sensu stricto) genotype 1 among cattle in Sudan. BMC Vet Res. 2018;14:36.

5. Casulli A, Manfredi MT, Laosa G, Cerbo AR, Genchi C, Pozio E. Echinococcus ortleppi and E. granulosus G1, G2 and G3 genotypes in Italian bovines. Vet Parasitol. 2008;155:168-72.

6. Zheng H, Zhang W, Zhang L, Zhang Z, Li J, Lu G, et al. The genome of the hydatid tapeworm Echinococcus granulosus. Nat Genet. 2013:45:1168-75.

7. Sadjjadi SM. Present situation of echinococcosis in the Middle East and Arabic North Africa. Parasitol Int. 2006:55:S197-202.

8. Zhang W, Zhang Z, Wu W, Shi B, Li J, Zhou X, et al. Epidemiology and control of echinococcosis in central Asia, with particular reference to the People's Republic of China. Acta Trop. 2015;141:235-43.

9. Economic survey of Pakistan, 2018-19. Ministry of Finance, Government of Pakistan. http://www.finance.gov.pk/survey/chapters_19/2-Agricultur e.pdf. Accessed 27 Dec 2019.

10. Ahmed H, Ali S, Afzal MS, Khan AA, Raza H, Shah ZH, et al. Why more research needs to be done on echinococcosis in Pakistan. Infect Dis Poverty. 2017;6:90.

11. Barazesh A, Sarkari B, Ebrahimi S, Hami M. DNA extraction from hydatid cyst protoscolices: comparison of five different methods. Vet World. 2018;11:231-4. 
12. Wu Y, Li L, Zhu G, Li W, Zhang N, Li S, et al. Mitochondrial genome data confirm that yaks can serve as the intermediate host of Echinococcus canadensis (G10) on the Tibetan Plateau. Parasit Vectors. 2018;11:166.

13. Ohiolei JA, Yan HB, Li L, Magaji AA, Luka J, Zhu G, et al. Cystic echinococcosis in Nigeria: first insight into the genotypes of Echinococcus granulosus in animals. Parasit Vectors. 2019;12:392.

14. Okonechnikov K, Golosova O, Fursov M, the UGENE team. Unipro UGENE: a unified bioinformatics toolkit. Bioinformatics. 2012;28:1166-7.

15. Tajima F. Statistical method for testing the neutral mutation hypothesis by DNA polymorphism. Genetics. 1989;123:585-95.

16. Fu YX. Statistical tests of neutrality of mutations against population growth, hitchhiking and background selection. Genetics. 1997;147:915-25.

17. Rozas J, Ferrer-Mata A, Sanchez-DelBarrio JC, Guirao Librado P, RamosOnsins SE, Sanchez-Gracia A. DnaSP v6: DNA sequence polymorphism analysis of large datasets. Mol Biol Evol. 2017;34:3299-302.

18. Bandelt HJ, Forster $P$, Rohl A. Median-joining networks for inferring intraspecific phylogenies. Mol Biol Evol. 1999;16:37-48.

19. Huelsenbeck JP, Ronquist F. MRBAYES: Bayesian inference of phylogeny. Bioinformatics. 2001:17:754-5.

20. Mueller RL, Macey JR, Jaekel M, Wake DB, Boore JL. Morphological homoplasy, life history evolution, and historical biogeography of plethodontid salamanders inferred from complete mitochondrial genomes. Proc Natl Acad Sci USA. 2004;101:13820-5.

21. Shen X, Wang H, Ren J, Tian M, Wang M. The mitochondrial genome of Euphausia superba (Prydz Bay) (Crustacea: Malacostraca: Euphausiacea) reveals a novel gene arrangement and potential molecular markers. Mol Biol Rep. 2010;37:771-84.

22. Wei SJ, Tang P, Zheng LH, Shi M, Chen XX. The complete mitochondrial genome of Evania appendigaster (Hymenoptera: Evaniidae) has low $\mathrm{A}+\mathrm{T}$ content and a long intergenic spacer between atp8 and atp6. Mol Biol Rep. 2010;37:1931-42.

23. Ali I, Maria KP, Aqib I, Iqbal M, Sohail A, Abid A. Molecular characterization of Echinococcus species in Khyber Pakhtunkhwa, Pakistan. Acta Sci Vet. 2015;43:1277-83.

24. Ehsan M, Akhter N, Bhutto B, Arijo A, Ali Gadahi J. Prevalence and genotypic characterization of bovine Echinococcus granulosus isolates by using cytochrome oxidase 1 (Co1) gene in Hyderabad, Pakistan. Vet Parasitol. 2017;239:80-5.

25. Latif AA, Tanveer A, Maqbool A, Siddiqi N, Kyaw-Tanner M, Traub RJ. Morphological and molecular characterisation of Echinococcus granulosus in livestock and humans in Punjab, Pakistan. Vet Parasitol. 2010;170:44-9.

26. Pednekar RP, Gatne ML, Thompson RC, Traub RJ. Molecular and morphological characterisation of Echinococcus from food producing animals in India. Vet Parasitol. 2009;165:58-65.

27. Bart JM, Abdukader M, Zhang YL, Lin RY, Wang YH, Nakao M, et al. Genotyping of human cystic echinococcosis in Xinjiang, PR China. Parasitology. 2006;133:571-9.

28. Zhang L, Eslami A, Hosseini SH, McManus DP. Indication of the presence of two distinct strains of Echinococcus granulosus in Iran by mitochondrial DNA markers. The Am J Trop Med Hyg. 1998;59:171-4.

29. Beyhan YE, Umur S. Molecular characterization and prevalence of cystic echinococcosis in slaughtered water buffaloes in Turkey. Vet Parasitol. 2011;181:174-9.

30. de la Rue ML, Takano K, Brochado JF, Costa CV, Soares AG, Yamano K, et al. Infection of humans and animals with Echinococcus granulosus (G1 and G3 strains) and E. ortleppi in southern Brazil. Vet Parasitol. 2011;177:97-103

31. Romig T, Ebi D, Wassermann M. Taxonomy and molecular epidemiology of Echinococcus granulosus sensu lato. Vet Parasitol. 2015:213:76-84.
32. Yanagida T, Mohammadzadeh T, Kamhawi S, Nakao M, Sadjjadi SM, Hijjawi N, et al. Genetic polymorphisms of Echinococcus granulosus sensu stricto in the Middle East. Parasitol Int. 2012:61:599-603.

33. Casulli A, Interisano M, Sreter T, Chitimia L, Kirkova Z, La Rosa G, et al. Genetic variability of Echinococcus granulosus sensu stricto in Europe inferred by mitochondrial DNA sequences. Infect Genet Evol. 2012;12:377-83.

34. Andresiuk MV, Gordo FP, Saarma M, Elissondo MC, Taraborelli A, Casalongue $\mathrm{C}$, et al. Echinococcus granulosus genotype G1 dominated in cattle and sheep during 2003-2006 in Buenos Aires province, an endemic area for cystic echinococcosis in Argentina. Acta Trop. 2013;127:136-42.

35. Nakao M, Li T, Han X, Ma X, Xiao N, Qiu J, et al. Genetic polymorphisms of Echinococcus tapeworms in China as determined by mitochondrial and nuclear DNA sequences. Int J Parasitol. 2010;40:379-85.

36. Wang J, Wang N, Hu D, Zhong X, Wang S, Gi X, et al. Genetic diversity of Echinococcus granulosus in Southwest China determined by the mitochondrial NADH dehydrogenase subunit 2 gene. Sci World J. 2014:2014:867839.

37. Boufana B, Lahmar S, Rebai W, Ben S, Jebabli L, Ammar A, et al. Genetic variability and haplotypes of Echinococcus isolates from Tunisia. Trans $R$ Soc Trop Med Hyg. 2014;108:706-71.

38. Mehmood N, Muqaddas H, Arshad M, Ullah Ml, Khan Zl. Comprehensive study based on mtDNA signature (nad1) providing insights on Echinococcus granulosus s.s. genotypes from Pakistan and potential role of buffalodog cycle. Infect Genet Evol. 2020;81:104271.

39. Grenouillet F, Umhang G, Arbez-Gindre F, Mantion G, Delabrousse E, MilIon $\mathrm{L}$, et al. Echinococcus ortleppi infections in humans and cattle, France. Emerg Infect Dis. 2014;20:2100-2.

40. Sharma M, Fomda BA, Mazta S, Sehgal R, Singh BB, Malla N. Genetic diversity and population genetic structure analysis of Echinococcus granulosus sensu stricto complex based on mitochondrial DNA signature. PLoS One. 2013;8:e82904

41. Shi Y, Wan $X$, Wang Z, Li J, Jiang Z, Yang Y. First description of Echinococcus ortleppi infection in China. Parasit Vectors. 2019;12:398.

42. Ebrahimipour M, Sadjjadi SM, Yousofi Darani H, Najjari M. Molecular studies on cystic echinococcosis of camel (Camelus dromedarius) and report of Echinococcus ortleppi in Iran. Iran J Parasitol. 2017;12:323-31.

43. Thapa NK, Armua-Fernandez MT, Kinzang D, Gurung RB, Wangdi P, Deplazes P. Detection of Echinococcus granulosus and Echinococcus ortleppi in Bhutan. Parasitol Int. 2017;66:139-41.

44. Zhang LH, Joshi DD, McManus DP. Three genotypes of Echinococcus granulosus identified in Nepal using mitochondrial DNA markers. Trans R Soc Trop Med Hyg. 2000;94:258-60.

45. Balbinotti H, Santos GB, Badaraco J, Arend AC, Graichen DA, Haag KL, et al. Echinococcus ortleppi (G5) and Echinococcus granulosus sensu stricto (G1) loads in cattle from southern Brazil. Vet Parasitol. 2012;188:255-60.

46. Cucher MA, Macchiaroli N, Baldi G, Camicia F, Prada L, Maldonado L, et al. Cystic echinococcosis in South America: systematic review of species and genotypes of Echinococcus granulosus sensu lato in humans and natural domestic hosts. Trop Med Int Health. 2016;21:166-75.

47. Omer RA, Dinkel A, Romig T, Mackenstedt U, Elnahas AA, Aradaib IE, et al. A molecular survey of cystic echinococcosis in Sudan. Vet Parasitol. 2010:169:340-6.

48. Romig T, Omer RA, Zeyhle E, Huttner M, Dinkel A, Siefert L, et al. Echinococcosis in sub-Saharan Africa: emerging complexity. Vet Parasitol. 2011;181:43-7

49. Mbaya H, Magambo J, Njenga S, Zeyhle E, Mbae C, Mulinge E, et al. Echinococcus spp. in central Kenya: a different story. Parasitol Res. 2014;113:3789-94.

50. Addy F, Wassermann M, Banda F, Mbaya H, Aschenborn J, Aschenborn O, et al. Genetic polymorphism and population structure of Echinococcus ortleppi. Parasitology. 2017;144:450-8.

51. Nakao M, McManus DP, Schantz PM, Craig PS, Ito A. A molecular phylogeny of the genus Echinococcus inferred from complete mitochondrial genomes. Parasitology. 2007;134:713-22.

\section{Publisher's Note}

Springer Nature remains neutral with regard to jurisdictional claims in published maps and institutional affiliations. 